\title{
A New Phenomenon in Saudi Females' Code-switching: A Morphemic Analysis
}

\author{
Mona O. Turjoman \\ Department of English Language and Literature, College of Arts, King Saud University, Riyadh, Saudi Arabia \\ Email: mturj@ksu.edu.sa
}

Doi:10.7575/aiac.alls.v.7n.6p.91

Received: 18/08/2016

URL: http://dx.doi.org/10.7575/aiac.alls.v.7n.6p.91

Accepted: 17/10/2016

\begin{abstract}
This sociolinguistics study investigates a new phenomenon that has recently surfaced in the field of code-switching among Saudi females residing in the Western region of Saudi Arabia. This phenomenon basically combines bound Arabic pronouns, tense markers or definite article to English free morphemes or the combination of bound English affixes to Arabic morphemes. Moreover, the study examines the factors that affect this type of code-switching. The results of the study indicate that this phenomenon provides data that invalidates Poplack's (1980) universality of the 'Free Morpheme Constraint'. It is also concluded that the main factors that influence this type of code-switching is solidarity and group identity among other factors.
\end{abstract}

Keywords: Code-switching, Saudi females, sociolinguistics, CS factors, morphemic analysis

\section{Introduction}

Much research has been done on the reasons, patterns, and structure of code-switching (CS). Although CS is not a new topic, it remains the interest of many researches due to the fact that new and interesting facts are discovered with every research

Research on CS deals with bilinguals and multilinguals during the stretch of a single conversation, and shows that CS typically occur between sentence boundaries or clause and even word boundaries. Elements involved in code-switching are often shown to be free morphemes or between free morphemes, and this caused Poplack's (1980) to suggest the 'Free Morpheme Constraint' in CS, and further claim that this is a universal feature in CS. .Contrary to this theory, the researcher observed a new phenomenon, namely, the expansion of CS to the word, namely the morphemic level, among a group of young Saudi females in their code-switching of Arabic and English.

The aim of the present research is to investigate this recent phenomenon, namely, attaching bound Arabic morphemes to English free morphemes and vice versa. I believe this research will widen the scope of linguistics in general and sociolinguistics in particular since, as to my best of knowledge, no study of this sort has been attempted on adult Arabic/English Saudi female bilinguals. Three studies carried out by Al-Sharif (2015) and Bader \& Minnis, (2000) and Bader (1998) examine CS among Arabic/English bilingual children found that the subjects add the Arabic bound definite article and the bound plural Arabic feminine morphemes to English nouns. But no studies have investigated this phenomenon among Saudi or Arab adults, except for Alsadeqi (2010). In addition, this study investigates the factors that influence the participants' CS.

\section{Background}

\subsection{Saudi Arabia and English}

English has become a widespread language in Saudi Arabia. Although English is not introduced until the fourth grade in public schools in Saudi Arabia, private and international schools are abundant throughout the country. Thus, very few educated youngsters of the last two generations do not speak English. As a matter of fact, many Saudis have been traveling abroad to English-speaking countries for the past few decades, if not for studies then for leisure. As a result, it is normal to hear Saudis slip in an English word or two while speaking even if their English proficiency level is not high. Grosjean (1982) states that an enormous number of the people around the world are bilingual even in countries where they are officially monolingual. In the Arab countries, those who are in command of both Arabic and English languages tend to code-switch much more frequently. Al-Hourani \& Afizah (2013:40) state that "Arabic-English code switching phenomenon is widely observed among Arab speakers."

\subsection{Theoretical background of CS}

As a basis of the current study, a distinction between borrowing and CS must be established. Many scholars have attempted to differentiate between the notion of borrowing and CS. Some linguists (Grosjean, 1982: Pandit 1990: Jacobson 1990: Hoffman 1991) agree that once an entity is assimilated phonologically and morphologically in a language it is considered as a borrowed item. When items are borrowed into the Arabic language, Alsadeqi (2010: 119) states that "... for borrowing to be accepted in Arabic, it has to undergo some phonological changes before being 
integrated ..." Scotton (1987) disagrees with this since she views integration to be unreliable and instead proposes frequency as a means to distinguish between the borrowing and CS. She states that borrowed forms "should be a distinguishable set from the embedded language which speakers know in some abstract sense, borrowings are available to many (or all) speakers, while embedded forms in switching are not" (p, 70). Borrowings are usually used in repeated forms and have specific lexical references, according to Mufwene \& Moshi (1993), but, if these entities are not used on a regular basis, this is considered a code-switching.

Code-switching, on the other hand, has been defined by numerous linguists. Gumperz (1982), defines code-switching as "the juxtaposition within the same speech exchange of passages of speech belonging to two different grammatical systems or subsystems..." Grosjean (1982) indicates that it is the utilization of a word, a phrase, a sentence or several sentences of more than one language in a single conversation. Milroy and Muysken (1995:7) give the following definition for code-switching, which is "the alternative use by bilinguals of two or more languages in the same conversation". Poplack (1980: 583) defines code-switching as "the alternation of two languages within a single discourse, sentence, or constituent." Bentahila and Davis (1983) indicate that CS is the "act of choosing one code rather than another must be distinguished from the act of mixing the two codes together to produce something which might itself be called a third code". For the sake of simplification, I shall refer to CS as any type of code-mixing of components from two languages within a single utterance by a single individual.

\subsection{Related studies on Arabic and English CS}

Some studies have looked at the factors behind CS in Arabic and English. Al-Hourani \& Afizah (2013) found that among Jordanian students in Malaysia, code-switching from Arabic to English occurred when the recipients are familiar to them. Murad (2013) studied Arab practicum guides and found that they tend to switch to Hebrew mainly due to the use of technical term. Bader (2003) states that non-English foreign nationals living in Jordan code-switched to Arabic to express a sense of belonging. Abalhassan and Alshalawi (2000: 179) found that Saudi graduate students in the United States "mostly used English words inserted into Arabic matrix," an indication of the influence of native structure on the CS words. In a study of perceptions toward CS, Hussein (1999) discovered that Jordanian university students show a combination of negative and positive attitudes towards CS between Arabic and English and the most important reason why they code-switch is lack of equivalence of certain English words and expressions in Arabic. Bader (1995) stated that many factors influence CS in English. He claimed that age, sex, region and education play a major role in CS. Other factors that influence their CS is setting, topic and age.

Alkhresheh (2015) investigated whether Arab students studying in India code-switch between Arabic and English. His findings revealed that these students do code-switch between the two languages. Murad (2013) found that Arab guides (instructors) tend to code-switch to Hebrew while teaching in the occupied territory due to the technical and scientific nature of the terms and for the sake of ease. Badr (2003) found that French, Italian and Russian residents in Northern Jordan code-switch to Arabic while communicating in English or French especially when the topic dealt with greetings, local festivals or religious occasions.

Many scholars have established that CS is done in a systematic manner governed by rules and constraints (e.g. Labov 1972 and Weinreich 1953). Weinreich (1953), the pioneer of CS studies, claimed that one cannot code-switch within a sentence or if there is no change in topic. Although this may be true, it is not always the factor behind CS. This claim was challenged and proved to be invalid by different studies (Blom and Gumperz, 1972 and Poplack, 1980 among others).

\subsection{Free Morpheme Constraint}

In her study, Poplack (1980) introduced constraints that are imposed on the process of CS. These constraints include the 'Equivalence Constraint' and the 'Free Morpheme Constraint'. These constraints have attracted many researchers and have caused controversy in the assumption of its universality. As stated by Poplack (1980:586), the 'Equivalent Constraint' is where

"...code-switches will tend to occur at points in discourse where juxtaposition of L1 and L2 elements does not violate a syntactic rule of either language, i.e., at points around which the surface structures of the two languages map onto each other. According to this simple constraint, a switch is inhibited from occurring within a constituent generated by a rule from one language which is not shared by the other."

Later studies have proved the violation of such a constraint and the invalidity of its universality (Ene 2011, Redouane, 2005, Badr, 2003, among others).

The current study focuses only on Poplack's (1980: 589) 'Free Morpheme Constraint' which states that "Codes may be switched after any constituent in discourse provided that the constituent is not a bound morpheme". A year later, Sankoff \& Poplack (1981:5) adjusted the 'Free Morpheme Constraint' by explicitly stating the prohibition of CS "between a bound morpheme and a lexical form unless the latter has been phonologically integrated into the language of the bound morpheme." The present study challenges this theory with a new phenomenon in Saudi female CS through the investigation of the universality of the 'Free Morpheme Constraint' by testing it against the data at hand.

Research on CS usually distinguishes between two types of CS, namely, inter-sentential and intra-sentential CS, the former being the easier to identify since it occurs between sentence boundaries at the sentence level and involves the use of two languages. The latter refers to the alternation of two or more languages between major constituent boundaries such as words or phrases. This type of CS is complex and requires morphological as well as syntactic 
analyses. Since the main focus of this study is to argue against the universality of Poplack's (1980) 'Free Morpheme Constraint' among Saudis, we will be dealing with intra-sentential CS.

\section{Method and Data Collection}

\subsection{Recordings}

Data were collected during a number of the weekly social gatherings among the participants. A total of three hours of naturally occurring conversation were recorded after receiving the participants' consent. The fragments chosen for the study formed a small specific sample of instances of CS of the interest to the current study. Personal interviews were also conducted with the participants to clarify the factors that influence the use of this new phenomenon in CS. A chart was then set to illustrate the most frequent factors.

The data recorded were transcribed phonetically and clear morphemic features were identified with the literal translation. The data were analyzed thoroughly in the light of Poplack's 'Free Morpheme Constraint'.

\subsection{Interviews}

Each of the participants was interviewed individually as to avoid influence of opinion. The main purpose of the interview was to investigate their opinion as to what factors influence CS. Participants were given a list of factors and were asked to choose the ones they thought were the most influential and to what degree in their choice to code-switch. Participants were also asked if they wanted to add to the list of factors. The percentage of each factor chosen was then place in a bar chart.

\subsection{Participants}

The participants of the current study were eight Saudi females between the ages of 23 and 27. All eight participants have been good friends since childhood. They all studied in private schools in Jeddah. Some of them went to the same schools. They all graduated from university and although their first language is Arabic, they are fluent in English and are thus considered bilingual. So, basically they all have similar educational backgrounds. One of the participants is the researcher's niece and this made the process of date collection and interviews feasible.

\section{Results and analysis}

\subsection{Evidence against the universality of Poplack's 'Free Morpheme Constraint'}

The results were analyzed against Poplack's 'Free Morpheme Constraint'. The examples clearly illustrate the phenomenon at hand. All eight participants contributed to some type of CS, but only a few examples are included for illustration. Through the process of analysis, it was realized that there are two main types of CS that were used by the participants at the morphemic level.

\subsubsection{Arabic/English morphemes}

In this part, we see the use of English bound morphemes with Arabic free morphemes, as shown in the following example.

1- Juf-ti fustan-ha? It was un-t'abi:乌i.

See-you dress-her? It was un-normal

Did you see her dress? It was un-realistic (out of this world)

In example (1), the participant asks a rhetorical question in Arabic and immediately answers it in English. However, just before she finishes her answer, she concludes her utterance with an Arabic free morpheme. This Arabic noun ' $t$ ' abi: $\mathrm{Y} i$ ' meaning 'normal' is attached to the English bound morpheme \{un-\}. In Arabic, a bound morpheme is permitted to be attached to a noun. Although in English it is typical to attach a bound morpheme to a noun, the bound morpheme \{un-\} is not the appropriate prefix to be attached to the noun 'normal' in English, if the speaker were to continue in English instead of attaching the Arabic word. During the interview with the participant who produced this utterance, it was clear that she was completely aware of the process of the morpheme $\{a b-\}$ in 'abnormal' but she also realizes that adding the prefix \{un-\} would be phonologically easier to produce. This type of CS obviously violates the 'Free Morpheme Constraint' which states that CS only occurs between free morphemes, and not bound morphemes. More examples are given below to further illustrate the point.

2- Can you believe it? Ma: PaStəzr-ət! Ihsa:s-less! Can you believe it? Not apologize-she! Feeling-less!

Can you believe it? She didn’t apologize! Insensitive!

In example (2), the speaker uses an Arabic noun and attaches the English bound suffix \{-less $\}$ to it. Arabic prohibits the use of a bound morpheme with nouns, except for the bound pronouns, whereas English allows it. The CS between the two languages highlights this new rising phenomenon in the trend of code switching. The participant expressed her awareness of this restriction but used it anyway. She argued that her friends knew exactly what she meant to say.

3- She has been kul məka:n. səfər-ha hudu:d-less.

She has been every place. Travel-her limits-less.

She has been everywhere. Her travels are limitless (unlimited). 
This example is similar to example (2) in the sense that the speaker attaches the English bound morpheme (-less) to the Arabic noun 'hudu:d' but differs in that this word is a plural noun. So again we have the addition of two morphemes to the stem 'had' (limit), the Arabic plural, which is a complicated process to achieve the outcome 'hudu:d', and the attachment of the English bound morpheme \{-less\}. The outcome is a complicated morpheme that seems to express what the speaker is trying to say more accurately than if she had chosen to use either Arabic or English completely.

\subsubsection{English/Arabic morphemes}

In this part, we show the analysis of the use of Arabic bound morphemes with English free morphemes, as in the following examples.

4- Look-aha ka:n xura:fi fi-l-party.

Look-her was fabulous in the party.

Her look (style) was fabulous at the party.

In Arabic, it is normal to attach a bound personal pronoun morpheme to a noun. However, we do not find this in English since English pronouns are free morphemes. But what is of interest here in that the participant who uttered example (4) starts with the English morpheme 'look' but attaches a bound Arabic third person pronoun suffix to the word. In English there are no bound pronouns, yet the speaker applies the Arabic third person bound pronoun to the English noun 'look'. The participant also attaches the definite bound Arabic prefix to the English morpheme 'party'. Both examples violate the structural rules of English, but code-switching occurs due to the syntactic possibility of the Arabic bound morphemes. Code now appears to include bound morphemes as elements that can be code-switched between Arab speakers of English.
5- A-wonder eif hə-tilbəs fi-l-wedding.
I wonder what will-she-wear in-the-wedding.
I wonder what she will wear at the wedding.

In example (5), the speaker attaches the Arabic bound first person pronoun prefix to the English word 'wonder', a structure that is allowed in Arabic but not English. This phenomenon has not been reported in any of the studies I have looked at on Arabic/English CS. As in example (4), the speaker goes on to bind the Arabic definite article to the English noun 'wedding'. This is a type of CS which has been reported to be used among Arabic/English adult bilinguals (Alsadeqi, 2010) and Arabic/English bilingual children (Al-Sharif, 2015; Bader \& Minnis, 2000; Bader, 1998).

6- ћə-a-check with her wə ?agu:1-lik.

Will-I-check with her and I-say to-you.

I'll check with her and let you know.

The first word in example (6) shows an interesting combination of CS. The English free morpheme 'check' has two Arabic bound prefixes attached to it. The first one is the future tense bound Arabic letter $\{$ hə- $\}$ which is followed by the Arabic prefix first person pronoun $\{-\mathrm{a}-\}$. The tense marker $\{\hbar \ni-\}$ is only used in colloquial Arabic and is not used in Modern Standard Arabic. In regards to the Arabic bound personal pronouns, they are immediately bound to Arabic nouns in both colloquial Arabic and Modern Standard Arabic. Therefore, the tense marker has to precede the pronoun. This was the only example of its kind from the data of the study. However, it provides further evidence of the codeswitching of bound morphemes and not just free morphemes.

7- Ye-tension kul elli around him.

He-tension all that around him.

He spreads tension to all those around him.

In example (7), the speaker attaches the Arabic bound third person pronoun $\{$ Ye- $\}$ to the English free morpheme 'tension' again violating the free morpheme constraint since it is a structure that is allowed in Arabic but not in English.

Through the process of analysis, it is obvious that there is a new CS phenomenon that is rising among Saudi females, in Jeddah in particular. The main finding this study is the use of either Arabic free morphemes with English bound affixes or the use of English free morphemes with Arabic bound morphemes by the Saudi participants even though the structure of either usage is allowed in one language but not the other. This clearly violates the universality of the 'Free Morpheme Constraint' proposed by Poplack (1980), which states that CS does not occur between a bound morpheme and a lexical form unless there is phonological integration. The examples do not show any form of phonological integration of either the switched bound morphemes or free words of the respective languages.

4.2 Factors that influence CSIn regards to the factors that influence CS, the interviews with the participants on revealed information that is illustrated in the following chart: 


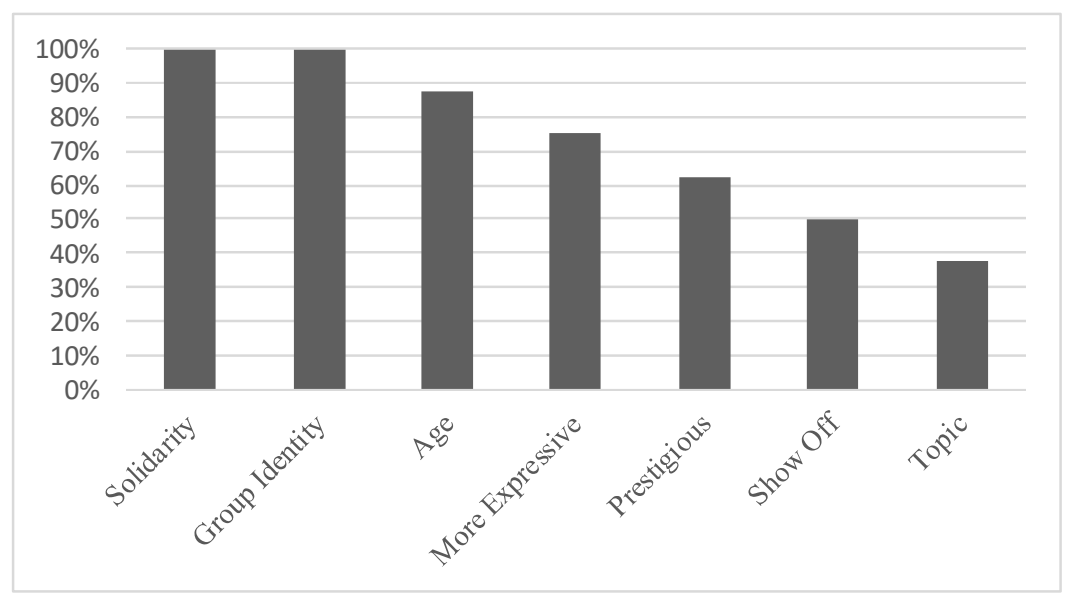

Figure 1. Factors that influence CS

It is noticeable from Figure (1) that all participants (100\%) agreed that they code-switch to express solidarity and group identity since such CS only occurs among close friends. Since the participants were long life friends, it is no surprise that they indicated this answer, as a way to express their relationship and show solidarity. The participants also felt that their group was unique and that this type of CS gave them a sense of identity. Seven of them (87.5\%) were strongly convinced that this phenomenon is age specific. They also believed that neither the older generation nor the younger age groups use this type of CS. Six out of the eight participants (75\%) found that CS is more expressive than just using one language. Five of them (62.5\%) subjects believed that CS is prestigious. They noticed that when they used this type of CS in public, they sometimes unintentionally attracted the attention of bystanders. Half of the group $(50 \%)$ admitted that they like to show off their skill of CS when they are in public. Only three of the participants (37\%) considered the topic of a conversation has an influence on their CS.

\section{Discussion}

It seems that studies in CS is in constant discovery of new phenomena. The participants of the study were between the ages of 23 and 27 and share similar backgrounds. The fact that they are good friends allows them to code-switch knowing fully well that they will be easily understood without any room for confusion or misunderstandings. The conversation recorded has ample data of CS although it is only a three hour recording of three different gatherings of the same participants to insure that the participants do actually code-switch consistently when they meet.

From the examples of CS presented in this study, it appears that the participants not only code-switched free morphemes, but also bound morphemes. The results suggest that code-switching incorporates the structural rules of one language into another; hence, structural constraints are violated for the ease of communication. Bound morphemes of both Arabic and English were found to be switched in the data. Arabic bound morphemes were switched and attached to English free morphemes, and English bound morphemes to Arabic free morphemes. There is violation in the English structural rules, but none for Arabic. The bound morphemes adhered nicely to Arabic syntax. Nonetheless, this CS process violates Poplack's (1980) 'Free Morpheme Constraint' which does not permit CS on the bound morpheme level.

The switched bound morpheme also cannot be seen as borrowing, because what is switched is not permanent. They do not attach to only particular words. In addition, borrowing involves lexical items and not bound morphemes. Also, the speakers were at ease in switching bound morphemes only with close friends in a casual conversation, as shown in the analysis.

\section{Conclusion}

This study was conducted to explore CS, among Saudi females, particularly in Jeddah. The finding shows the rising trend of a new phenomenon in CS which is the attaching of English bound affixes to free Arabic morphemes, as well as, attaching Arabic bound morphemes to English free morphemes. This new phenomenon involves CS on the word level. This concept clearly shows that the universality of Poplack's (1980) 'Free Morpheme Constraint' requires rethinking, as bound morphemes do get code-switched in the speech of the Saudi bilinguals in the study. The current study supports the results of several other studies that have also proven the invalidity of Poplack's universal claim (e.g., Ene 2011 of Romanian-English CS, Alsadeqi 2010 of integrating English words into Arabic, Redouane 2005 on Moroccan ArabicFrench CS, Badr 2003 on the CS of foreign nationals of Arabic/English CS and Bader \& Minnis' 2000 study of an Arabic/English bilingual child, among others). Further, the participants indicated that the main reasons they codeswitched are solidarity and group identity, among other factors.

This phenomenon is worth further research to investigate code-switching behaviors, particularly among speakers of Arabic, and factors that cause the switching of bound morphemes, other than those presented in the individual interviews. It would also be interesting to see if natural data show otherwise among male and female subjects of any age 
groups in the Arabic-speaking community. Similarly, a cross-cultural study of the CS phenomenon is suggested to further support or dispute Poplack's theory of code-switching.

\section{Acknowledgement}

This is a research project that was supported by a grant from the Research Center for the Humanities, Deanship of Scientific Research at King Saud University.

\section{References}

Abalhassan, K., \& Alshalawi, H. (2000). Code-switching behaviour of Arab speakers of English as a second language in the United States. Intercultural Communication Studies, 10(1), pp. 179-188.

AL-Hourani, A., \& Afiza, T. (2013). Code switching in daily conversation. International Journal of Social Science and Humanities Research, 1(1), pp. 40-43.

Alkhresheh, M. (2015). Code-switching and mixing of English and Arabic among Arab students at Aligarh Muslim University in India. International Journal of Scientific and Research Publications, 5(2), pp. 1-4.

Alsadeqi, F. (2010). Integrating English words into Gulf Arabic. International Journal of Arts and Sciences, 3 (10), pp. 115-129.

Al-Sharif, A. (2015). Three-year-old English-Arabic Bilingual: Notes on Syntictic code-switching. International Journal of Humanities and Cultural Studies, 2 (1), pp. 71-89.

Bader, Y., \& Minnis, D. (2000). Morphological and syntactic code-switching in the speech of an Arabic-English bilingual child. Multilingua, 19(4), pp. 383-403.

Bader, Y. (1995). Codeswitching to English in daily conversations in Jordan: Factors and attitudes. Abhath Al-Yarmouk, 13 (1), pp.9-27.

(1998). Lexical Codeswitchingin the speech of an Arabic-English Bilingual child. Interface, 13(1), pp. 3-17.

(2003). Some characteristics of codeswitching to Arabic among non-English foreign nationals in Jordan.

Damascus University Journal, 19 (3+4), pp. 35-52.

Bentahila, A. \& Davies, E. (1983). The syntax of Arabic-French code-switching. Lingua, 59(4), pp. 301-330.

Blom, J. P., \& Gumperz, J.J. (1972). Social meaning in linguistic structures: Codeswitching in Norway. In J.J.

Ene, E. (2011). Romanian-English code-switching: A preliminary study. Arizona Working Papers in SLAT, 8, pp.4555.

Grosjean, F. (1982). Life with Two Languages: An Introduction to Bilingualism. Cambridge, Mass. Harvard University Press.

Gumperz, J. (1982). Discourse Strategies. New York, NY: Cambridge University Press.

Hoffmann, C. (1991). An Introduction to Bilingualism. London and New York: Longman.

Jacobson, R. (ed). (1990). Codeswitching as a worldwide phenomenon.New York: Peter Lang.

Labov, W. (1972). Language in the Inner City.Philadelphia: University of Pennsylvania Press.

Milroy, L. \& Muysken, P. (eds). (1995). One Speaker, Two Languages: Cross-Disciplinary Perspectives on Codeswitching. New York, NY: Cambridge University Press.

Mufwene, S. \& Moshi, L. (1993). Topics in African Linguistics. Philadelphia, PA: John Benjamins.

Murad,T. (2013). Arab Practicum Guides Code-switch to Hebrew: Attitudes, Factors and Reasons. Journal of Language Teaching and Research, 4(6), pp. 1160-1166.

Owens, J. (2005). Hierarchicalized matrices: codeswitching among urban Nigerian Arabs. Linguistics, 43, pp. 957-993.

Pandit, I. (1990). Grammaticality in code-switching. In Rodolfo Jacobson (ed), 33-69.

Poplack, S. (1980). Sometimes I'll start a sentence in Spanish y termino en espanol. Linguistics 26, 581-618.

Redouane, R. (2005). Linguistic constrains on codeswitching and codemixing of bilingual Moroccan Arabic-French speakers in Canada. Proceedings of the $4^{\text {th }}$ International Symposium on Bilingualism, pp. 1921-1933.

Sankoff, D. \& Poplack, S. (1981). A formal grammar for code-switching. Paper in Linguistics: International Journal of Human Communication, 14(1), pp.3-45.

Scotton, C. (1987).Code switching and types of multilingual communities. In Georgrtown University Round Table. Pp. 61-82.

Taweel, A. \& Btoosh, M. (2012). Syntactic aspects of Jordanian Arabic-English intra-sentenial code-switching. Linguistica, http://www.phil.muni.cz/linguistica/art/taweelbtoosh/tab-001.pdf

Weinreich, U. (1953). Languages in contact. The Hague: Mouton. 